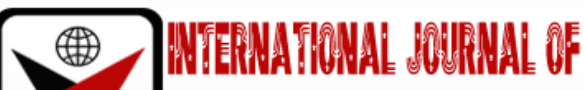

ISSN 2278-0211 (Online)

\section{Potency of Blended Strategy on Students' Performance in Algebra at Senior Secondary Schools}

Ganiyu A. Iroko
Ph.D. Candidate, Department of Science \& Technology Education,
Lagos State University, Ojo, Lagos State, Nigeria
Adetunji A. Olaoye
Professor, Department of Science \& Technology Education
Lagos State University, Ojo, Lagos State, Nigeria

\begin{abstract}
:
This study investigated the potency of blended strategy on students' academic performance in algebra at senior secondary schools. It is meant to adopt an alternative method of teaching mathematics in order to proffer solution to the problems facing teaching and learning of mathematics. As a quasi-experimental study which comprised of SS 2 students in Ogun State, 161 students in four intact classes were involved in the study. A-16 item blended demographic instrument was used to collect data from teachers and students in chosen population to select schools that involved in blended strategy before the commencement of the treatment. Afterward, A-50 item multiple choice achievement test on algebra ( $r=0.93)$ and 20 item altitudinal questionnaire (0.78) were administered on the selected sample, where the exercise lasted for 12 weeks. Data analysis was done via Mean, Standard deviation and Multivariate Analysis of Covariance (MANCOVA) at $\alpha=0.05$ level of significance. The findings revealed that; there is statistically significant effect of blended strategy on students' performance in algebra. Based on the findings, it was recommended that concept blended strategy should be introduced to alleviate perennial academic backwardness of students in Mathematics in the Nigerian senior secondary schools.
\end{abstract}

Keywords: Blended strategy, achievement, attitude, performance algebra

\section{Introduction}

In considering how to best prepare students for the challenges of the twenty-first century, as well as to tackle the effects of COVID-19 pandemic on teaching and learning of mathematics. Mathematics education stakeholders are; (a) replacing traditional method of teaching with a variety of learning activities that move students from an inactive, notetaking role to an active learning orientation (b) redefining the content of the mathematics curriculum and the ways it is being taught at the secondary school level, (c) asking questions that extend students' thinking, guiding students' explorations, encouraging students to actively convey their thinking, and ultimately improving the quality of learning, (d) preparing a curriculum that improves students' abilities to reason, think, investigate, and communicate mathematically rather than a focus on computational skills (e) teaching students to construct their conceptual understanding of mathematics (d) providing regular opportunities for students to independently and collaboratively investigate and solve problems in order to improve their mathematical skills in the context of exploration. With the rapid pace of change in society, regular changes in educational patterns have been made from time to time to meet the needs of society (Ayuba and Timayi 2018).

The content of old Mathematics curriculum (NERDC 1985) was filled with elements of the capital market studies, which carefully structured, resulting in the removal of obsolete topics and addition of modern topics that are relevant to the global world. The team that prepared the new curriculum made efforts to ensure that topics that will improve the mathematical competency of Nigeria students as well as prepare them for further and tertiary education (NERDC 2007). In view of the fact that development of entrepreneurial skills is being promoted in Nigeria, the new curriculum also added few introductory topics in matrices, modular arithmetic and simple calculus which are hitherto restricted to further mathematics but which will enhance the competency of students in various vocations they will pursue at tertiary levels. The themes have changed from six-pronged approach to a five-pronged approach as follows: Number and numeration, Algebraic processes, Geometry, Statistics and Introductory calculus (NERDC 2007). Among the themes mentioned, algebraic processes serve as a connecting bridge that connects other themes of mathematics.

Algebra is a branch of mathematics that uses letters in place of numbers. Algebra, as a gateway of mathematics, is one of the areas of mathematics in which students have major problems (Usman and Musa 2019). Students' poor Algebra performance can be traced to mistakes made by students while attempting to solve algebraic problems, which can be procedural, conceptual, or both (Eisenhart, Borko, Underhill., Brown, Jones, \&Agard, 1993). Procedural errors are linked to 
procedural knowledge, which refers to the puzzle of computing abilities and procedural knowledge for defining mathematical components, algorithms, and concepts. while Conceptual errors are linked to conceptual knowledge, which is the understanding of mathematics' underlying structure, the relationships and interconnections of concepts that clarify and give meaning to mathematical processes.

Algebra as a branch of mathematics is vulnerable to gender studies (Akinsola and Awofala, 2009). This is because many people have speculated that the stereotypically masculine content of mathematics word problems may explain some of the gender differences in performance on such objects. While Arigbabu and Mji (2004) did not confirm the popular hypothesis that gender-stereotyped content of mathematics word problems would affect performance. It is expected that the educational experience provided to students in schools does not discriminate between men and women. There is the need to see that both male and female students are given equal access to learning of mathematics.

Students' algebraic performance in this context is being referred to as students' academic achievement in Algebra and students' attitude toward Algebra. Academic achievement is the quality of students' scores in a test or examination when compare with that of others of the same level. It is the quality of students' result that is reflected in their result or examination (Ginga, Muhammed and Usman 2019). A learned predisposition to respond positively or negatively to a particular object, situation, institution, or person is known as attitude (Aiken's 2000). Therefore; People's attitudes influence what they do and represent who they are, making them a deciding factor in their behaviour (Lin, Tseng, and Chiang 2017). There are several variables that usually determined students' performance, attitude is regarded by several researchers as an important factor to consider when attempting to understand and explain variability in student performance in mathematics (Mohamed \&Waheed, 2011)

Research evidences revealed that poor performance of students in mathematics is attributed to teaching method, mathematics phobia, lack of teaching materials, poor teaching facilities that include instructional materials and equipment for effective teaching (Ginga, Muhammed and Usman 2019). Mcguire (as cited in Joefel 2014) identified three suspected factors affecting underachievement in mathematics that include; Teachers' factor which is composed of communication skills, instructional techniques and strategies, classroom management, mastery of the subject matter and personality. Second is students' factor which includes time management, study habit, attitude and interest towards mathematics. Third are environmental factors such as values, classroom setting, attitude, parents and peer group. It was suggested that because teachers are often the primary contributors and have the greatest effect on student achievement, teachers should go above and beyond to reach out to students and assist them in developing critical thinking skills. In light of the foregoing, teaching strategies emphasizing practical ways of teaching and learning mathematics that can accommodate new technology and critical thinking within the situation of active learning are required. One of such strategy is concept mapping.

Blended learning is a newly developed teaching strategy that has largely replaced e-learning in most educational institutions. Salameh (2005) posited that in most developed modern learning methods, a blended approach is an appropriate and viable alternative to e-learning, which generates higher returns and requires lower costs. It is the process of adapting the traditional roles of teachers with the roles of the e-teacher in classes. Thus, it is a learning which integrates traditional and electronic learning. Blended learning allows learners to listen, visualize, feel, and interact with the learning material. It takes them from theory to practice, allowing them to achieve a better understanding of all the abstract concepts. They learn according to their pace, which creates the opportunity for more individualized education. Good achievers expand their learning and learn things that are not within the school syllabus. Slow learners, on the other hand, repeat and revise notes and seek input from their professors in order to overcome difficulties and challenges (Bailey and Martin, 2013). According to Kuo, Blland, Schroder, and Walker (2014), Blended learning is a method of learning that integrates face-to-face relationships with technology. Blended learning, also known as blended learning, is based on faceto-face interactions for $67 \%$ of the time and technology interactions for $33 \%$ of the time.

According to Gynther (2005) the term 'blend learning' was first used in American literature to describe a combination of traditional teaching and technology-based teaching that used various forms of technology to support a wide range of pedagogical practices. Blended learning combines face-to-face and online learning to help you improve the classroom experience and extend learning through the creative application of information and communication technology. (Clark, 2012). Blended learning is defined as learning that is facilitated by the efficient combination of various modes of delivery, teaching models, and learning styles, and is based on open communication among all participants in a course. (Heinze and Procter 2004).

According to Wilson (2013) blended learning can be categorized into six models in provisions of their delivery.

- The face-to-face model: It encourages teachers to use technology in the classroom in specific circumstances. It is suggested to assist students who are more capable than their peers in advancing ahead and achieving better learning outcomes, as well as students who are having difficulty keeping up with the class pace.

- The rotation model: According to pre-scheduled meetings, students must rotate their learning environment from a conventional classroom to a lab. It allows students to learn by using online resources and figuring out how things work.

- The flex model: It is designed for students who have behavioural, academic, or social problems and includes full online learning under the supervision and guidance of a teacher. It creates a more secure learning environment for them.

- Online lab model: This model requires students to go to an online lab to take certain classes, not because of the difficulties discussed above with the flex model, but rather because of the school's constraints, such as not offering that course. Furthermore, the students' work in the lab is supervised by adults rather than professors. In addition to having access to courses not offered at the school, students can work at their own pace. 
- The self-blend model: It's a model that involves students choosing their own subjects to learn, and it meets the needs of high school students looking for extra courses to help them get into university or find work.

- Online model: It's a model in which students with limited time should meet their professors online and then come in for face-to-face classes or meetings on a case-by-case basis. By improving its outputs, this model provides a high level of flexibility, opening up new possibilities for self-learning as well as lifelong learning.

\section{Statement of the Problem}

Many students struggle to learn mathematics and often do not achieve success through their learning. This may stem from the fact that; they do not construct appropriate understanding of fundamental mathematics concepts through their learning strategies. Reports from the WAEC Chief examiners (Mathematics) from May/June 2008 to May/June 2018 SSCE shows the weaknesses of students in Algebra theme ranging from word problems leading to simple linear equation, algebraic graph, reading/answering from the graph, interpretation/solution to word problems, translation of word problems into mathematical expressions, inequality and graphical solutions to quadratic equations. Mathematics result analysis from those periods (May/June 2008 to May/June 2018 SSCE) also shows that students' performance in mathematics has been fluctuating. Algebra as a bridge between themes in mathematics is one of the areas of mathematics in which students have major problems. The knowledge of Algebra and its correct application help both individuals and nations to solve everyday problems. In spite of the role played by Algebra in the development of science and the current efforts in mathematics instruction, there is still persistent poor performance of students in that area (Usman and Musa 2019) meanwhile, due to students' poor performance in algebra, it appears that various interactive tasks, approaches, and instructional methods are required for teaching and learning algebraic literacy in classrooms (Azuka, Jekayinfa, Durojaiye \& Okwuoza, 2013). Despite the high position offered to mathematics in Nigerian education system, it is disheartening that methods and strategies for teaching and learning this subject at both the primary and secondary levels are unlikely to be put to good use in order to encourage learners' activity and provide guided practice, allowing them to maintain ideas and solve problems (Achor, Imoko \& Uloko 2009). Although the aforementioned problems may not be solely rooted in the method of instruction only but the ways students are taught greatly affect their performance. However, evidence has abounded in recent years showing that blended teaching presents content in an appealing way, owing to various effects, allowing for meeting the various levels of students and designing activities that are appropriate to their actual levels (Yaghmor 2016). Therefore, a study towards adopting an alternative method of teaching is necessary in order to proffer solution to this problem. It is in view of this that the researcher decided to investigate the potency of blended strategy on students' performance in algebra at the senior secondary school level in Ogun State Senior secondary Schools.

\section{Research Questions}

The following research questions were formulated to guide the study:

- What is the effect of blended strategy on students' achievement in algebra?

- What is the effect of blended strategy on students' attitude toward algebra?

\section{Null Hypotheses}

Based on aforementioned research questions, the following hypotheses were generated.

- $\quad \mathrm{H}_{01}$ There is no statistically significant effect of blended strategy on students' achievement in algebra

- $\mathrm{H}_{\mathrm{o} 2}$ There is no statistically significant effect of blended strategy on students' attitude towards algebra

\section{Methodology}

The study employed a quasi-experimental pretest, posttest nonequivalent control group design. The study population for study comprised public senior secondary schools in Ogun State. The population includes both male and female students and other members of public senior secondary schools in Ogun State. Multistage sampling techniques were adopted in selecting sample for this study. Firstly, simple random sampling technique was used to select two divisions out of the four education blocs in Ogun State. Four public senior secondary schools were assigned to the experimental group and control group. Two of schools were purposively assigned to experimental group due to the involvement of technological gadgets and this was done through the use Blended demographic Instrument while the other two schools that served as control group were randomly selected. One arm in each of the sampled schools was used and intact class was adopted for the study since random assignment of the students to the groups was not achieved. Participants in blended strategy group were exposed to two-way learning method; face-to-face learning and online learning. An invitation to online blended classroom was sent to each participant that was part of blended strategy through gmail address submitted to the researcher where student created password and username for themselves before they could have access to blended classroom while those that were unable to receive the invitation via gmail address joined the class via http://bit.ly/blendedambassadors.

A self-explanatory lesson note on focused topic for each week would have been uploaded in the classroom a day before the commencement of the class and a link would be shared on Facebook group account (www.facebook.com/blendedclassroom) where students will have access to the lesson before the traditional classroom next day. The active face-to-face class was divide into three stages; The pre-computer session which was mainly the traditional face-to-face method of teaching that follows traditional step by step method in traditional classroom using traditional teaching method; the computer section where students launched into the blended classroom through Google Chrome or Sign In into the blended strategy Facebook account (www.facebook.com/blended classroom) and click on the link to the blended classroom platform, from the classroom they will click on the appropriate lesson and start learning 
independently, teacher moves round the class to render helps to the students when necessary; and post computer session where teacher reviews the lesson and ask students questions. Class would be concluded and next is for the students to meet the facilitators online on Facebook where the outcome of the short test attempted by the students at the end of each topic were discussed, also challenges faced by the students when solving class exercises and other related issue on the topic during the class were attended to by the facilitators. Appraisal of Online events were done before the commencement of the next class throughout the study. After the treatment, the participant took part in the post achievement test and post attitude questionnaire individual. Facebook was chosen ahead as WhatsApp and others for social network platform for the study because of the higher percentage of students that choose Facebook as their most frequently used social network with the aid of Blended Survey Instrument.

The instruments used for the study were BSI, ATA and AQA. A-16 item Blended Survey Instrument (BSI) was used to collect data from teachers and students in chosen population to select schools that were involved in blended strategy before the commencement of the treatment. Achievement Test in Algebra (ATA) which consisted of 50 items multiple choice questions on selected topics in Algebra and Attitude Questionnaire in Algebra (AQA) were administered to the two groups before and after the treatment which lasted for 12 weeks. The instruments were given to experts in Mathematics Education for some structural corrections, adjustments and suggestions to enhance the final production ahead of administration. The instruments ATA and AQA were subjected to reliability test using the Kuder-Richardson's formula K- R 21 and Cronbach's Alpha with the coefficient of reliability found to be 0.93 and 0.78 respectively. This score suggested that the instruments were found to be useful and consistent for the purpose for which they were prepared.

The data collected was subjected to statistical tool of Mean, Standard Deviation and Multivariate Analysis of Covariance (MANCOVA) using SPSS to test the efficacy of experimental group over control group. An alpha level of 0.05 was used to test the hypotheses.

\section{Findings}

- Research Question 1: What is the effect of blended strategy on students' achievement in algebra?

\begin{tabular}{|c|c|c|c|}
\hline METHOD & Mean & Std. Deviation & N \\
\hline BLENDED & 38.9375 & 6.76616 & 80 \\
\hline TRADITIONAL & 19.5926 & 4.83161 & 81 \\
\hline
\end{tabular}

Table 1: Mean And Standard Deviation of Student's Achievement Scores in Algebra Source: Field Data

Table 1 shows that students taught with blended learning strategy had the higher mean score (Mean $=38.94$, S.D $=$ 6.77) while the students taught with traditional method had the lowest mean score (Mean $=19.59,4.83$ ) in the post-test of algebraic achievement test. To ascertain whether the observed effect was significant, null hypothesis 1 was tested.

- $\mathrm{H}_{01}$ There is no statistically significant effect of blended strategy on students' achievement in algebra.

This hypothesis was tested using the multivariate analysis of covariance (MANCOVA) statistical technique at $\mathrm{p}<$ 0.05 significance. The result of the MANCOVA is shown in tables 2 and 3

\begin{tabular}{|c|c|c|c|c|c|c|}
\hline \multicolumn{2}{|c|}{ Effect } & Value & $\mathbf{F}$ & Hypothesis df & Error df & Sig. \\
\hline \multirow{4}{*}{ Intercept } & Pillai's Trace & .625 & $128.472^{\mathrm{b}}$ & 2.000 & 154.000 & .000 \\
\cline { 2 - 7 } & Wilks' Lambda & .375 & $128.472^{\mathrm{b}}$ & 2.000 & 154.000 & .000 \\
\cline { 2 - 7 } & Hotelling's Trace & 1.668 & $128.472^{\mathrm{b}}$ & 2.000 & 154.000 & .000 \\
\cline { 2 - 7 } & Roy's Largest Root & 1.668 & $128.472^{\mathrm{b}}$ & 2.000 & 154.000 & .000 \\
\hline \multirow{4}{*}{$\begin{array}{c}\text { PREACHIEVEM } \\
\text { ENT }\end{array}$} & Pillai's Trace & .195 & $18.672^{\mathrm{b}}$ & 2.000 & 154.000 & .000 \\
\cline { 2 - 7 } & Wilks' Lambda & .805 & $18.672^{\mathrm{b}}$ & 2.000 & 154.000 & .000 \\
\cline { 2 - 7 } & Hotelling's Trace & .242 & $18.672^{\mathrm{b}}$ & 2.000 & 154.000 & .000 \\
\cline { 2 - 7 } & Roy's Largest Root & .242 & $18.672^{\mathrm{b}}$ & 2.000 & 154.000 & .000 \\
\hline PREATTITUDE & Pillai's Trace & .050 & $4.053^{\mathrm{b}}$ & 2.000 & 154.000 & .019 \\
\cline { 2 - 7 } & Wilks' Lambda & .950 & $4.053^{\mathrm{b}}$ & 2.000 & 154.000 & .019 \\
\cline { 2 - 7 } & Hotelling's Trace & .053 & $4.053^{\mathrm{b}}$ & 2.000 & 154.000 & .019 \\
\cline { 2 - 7 } & Roy's Largest Root & .053 & $4.053^{\mathrm{b}}$ & 2.000 & 154.000 & .019 \\
\hline \multirow{4}{*}{ METHOD } & Pillai's Trace & .713 & $191.538^{\mathrm{b}}$ & 2.000 & 154.000 & .000 \\
\cline { 2 - 7 } & Wilks' Lambda & .287 & $191.538^{\mathrm{b}}$ & 2.000 & 154.000 & .000 \\
\cline { 2 - 7 } & Hotelling's Trace & 2.488 & $191.538^{\mathrm{b}}$ & 2.000 & 154.000 & .000 \\
\cline { 2 - 7 } & Roy's Largest Root & 2.488 & $191.538^{\mathrm{b}}$ & 2.000 & 154.000 & .000 \\
\hline
\end{tabular}

Table 2: Table Showing the Multivariate Tests of Students' Performance Source: Field Data

The Wilks' Lambda associated with the instructional method was significant $\left(\left(F_{(2,159)}=191.54, p<0.05\right)\right.$ which necessitated further probes into between subjects. 


\begin{tabular}{|c|c|c|c|c|c|c|}
\hline Source & Dependent Variable & $\begin{array}{l}\text { Type III Sum } \\
\text { of Squares }\end{array}$ & Df & $\begin{array}{c}\text { Mean } \\
\text { Square }\end{array}$ & $\mathbf{F}$ & Sig. \\
\hline \multirow[t]{2}{*}{ Corrected Model } & POSTACHIEMENT & $16207.739^{a}$ & 5 & 3241.548 & 115.810 & .000 \\
\hline & POSTATTITUDE & $707.613^{b}$ & 5 & 141.523 & 4.370 & .001 \\
\hline \multirow[t]{2}{*}{ Intercept } & POSTACHIEMENT & 925.510 & 1 & 925.510 & 33.065 & .000 \\
\hline & POSTATTITUDE & 7075.078 & 1 & 7075.078 & 218.483 & .000 \\
\hline \multirow{2}{*}{$\begin{array}{l}\text { PREACHIEVEME } \\
\text { NT }\end{array}$} & POSTACHIEMENT & 1046.599 & 1 & 1046.599 & 37.391 & .000 \\
\hline & POSTATTITUDE & 15.048 & 1 & 15.048 & .465 & .496 \\
\hline \multirow[t]{2}{*}{ PREATTITUDE } & POSTACHIEMENT & .039 & 1 & .039 & .001 & .970 \\
\hline & POSTATTITUDE & 264.028 & 1 & 264.028 & 8.153 & .005 \\
\hline \multirow[t]{2}{*}{ METHOD } & POSTACHIEMENT & 10529.068 & 1 & 10529.068 & 376.168 & .000 \\
\hline & POSTATTITUDE & 171.650 & 1 & 171.650 & 5.301 & .023 \\
\hline \multirow[t]{2}{*}{ Error } & POSTACHIEMENT & 4338.498 & 155 & 27.990 & & \\
\hline & POSTATTITUDE & 5019.331 & 155 & 32.383 & & \\
\hline \multirow[t]{2}{*}{ Total } & POSTACHIEMENT & 157868.000 & 161 & & & \\
\hline & POSTATTITUDE & 529158.000 & 161 & & & \\
\hline \multirow[t]{2}{*}{ Corrected Total } & POSTACHIEMENT & 20546.236 & 160 & & & \\
\hline & POSTATTITUDE & 5726.944 & 160 & & & \\
\hline
\end{tabular}

Table 3: Tests of Between-Subjects of Effects Instructional Strategies and Students' Performance

Source: Field Data

The F-value associated with Pre-Achievement Test (Covariate) was found to be significant. $\left[\mathrm{F}_{(1,159)}=37.39 ; \mathrm{p}<.05\right]$. This confirms that the students in the two groups were significantly difference in the achievement level in Algebra before the application of the treatment.

- Ho1: The result in table 3 showed that there is statistically significant effect of blended strategy on students' achievement in Algebra.

$[\mathrm{F}=376.17 ; \mathrm{p}<.05]$

Therefore, the null hypothesis which states that there is no statistically significant effect of blended strategy on students' achievement in Algebra is hereby rejected.

The study revealed that there is a differential effect of blended strategy and traditional method on students' algebraic achievement scores.

- Research Question 2: What is the effect of blended strategy on students' attitude toward algebra?

\begin{tabular}{|c|c|c|c|}
\hline Method & Mean & Std. Deviation & N \\
\hline Blended & 57.7250 & 4.53112 & 80 \\
\hline Traditional & 56.3210 & 7.09371 & 81 \\
\hline
\end{tabular}

Table 4: Mean and Standard Deviation of Students Attitudinal Scores in Algebra Source: Field Data

Table 4 shows that students taught with blended strategy had the higher mean score $($ Mean $=57.83$, S.D $=7.27)$ while the students taught with traditional method had the lowest mean score (Mean $=56.32$, S.D $=7.09$ ) in the post-test of student's attitudinal questionnaire toward algebra. To ascertain whether the observed effect was significant, null hypothesis 2 was tested.

- $\mathrm{H}_{02}$ : There is no statistically significant effect of blended strategy on students' attitude towards algebra

This hypothesis was tested using the multivariate analysis of covariance (MANCOVA) statistical technique at p< 0.05 significance. The result of the MANCOVA is shown in tables 2 and 3.

The F-value associated with Pre-Attitude Test (Covariate) was found to be significant. $\left[F_{(1,159)}=8.15 ; p<.05\right]$. This confirms that the students in the two groups were significantly difference in the attitudinal level toward Algebra before the application of the treatment.

- Ho1: The result in table 3 showed that there is statistically significant effect of blended strategy on students' attitude toward Algebra.

$\left[\mathrm{F}_{(1,159)}=5.30 ; \mathrm{p}<.05\right]$

Therefore, the null hypothesis which states that there is no statistically significant effect of blended strategy on students' attitude toward Algebra is hereby rejected. The study revealed that there is a differential effect of blended strategy and traditional method on students' algebraic attitude scores.

\section{Discussion}

This study investigated the potency of blended strategy on students' performance in Algebra at senior secondary level. The study revealed that blended strategy improves students' performance in Algebra compare to traditional method of teaching. Corroborating this study are; Awodeyin, Akpan, and Udo (2014) who discovered that using a blended learning approach increases students' pre-algebra achievement scores when compared to other approaches. According to the findings of a study conducted by Yaghmor (2016), there is a statistically significant difference in the performance of the two study groups in the items of the achievement test in Mathematics as a whole, and on behalf of the experimental group 
who was taught using blended teaching methods. Other studies that supported the efficacy of blended strategy over traditional approach in improving students' academic achievement include Ilorah, Adeniji \& Odeyemi (2018), Lin Y, Tseng C and Chiang P (2017), Brandy (2016), Fakhir (2015) and Almasaeid (2014). According to Almasaeid (2014) Students may use a blended learning strategy to coordinate their information, attitudes, and educational experiences by using multimedia provided by contemporary technology or information technology.

In contrast; According to Hinampas, Murillo, Tan, and Layosa (2018), there was no substantial difference in academic achievement between students exposed to blended learning and those exposed to non-blended learning; both increased their performance. Non-significant difference between academic achievement of students exposed to blended and traditional approaches is also supported by Cracaft (2015).

This finding was supported by studies carried out by Lin Y, Tseng C and Chiang P (2017), Fakhir (2015) and Almasaeid (2014) which found that blended learning was more effective than traditional methods in improving students' attitudes toward mathematics. The study of Banal (2017) also found significant difference exists in the mean scores of students' attitude towards science before and after the use of scaffolding teaching strategy in the experimental group.

\section{Conclusion}

Aside from the fact that Algebra plays prominent role towards attainment of teaching and learning of mathematics, it is also served as a bridge between mathematics themes. Its importance to everyday activity also cannot be over emphasized.

This study investigated the potency of blended strategy on students' performance in algebra. The findings from the study revealed that; there is statistically significant effect of blended strategy on students' performance in algebra.

\section{Recommendations}

Considering the problems identified and based on the findings of this study, thus the followings are recommended:

- Secondary school teachers should be motivated and encouraged to discontinue the use of traditional method in the teaching of mathematics particularly Algebra concepts.

- Mathematics teachers at the secondary school level are urged to adopt multichannel based strategy of instruction like blended strategy that have potential of improving students' performance in Mathematics.

- Since blended strategy enhances the meaningful learning of Algebra, there is therefore the need to further train teachers on the use of this instructional strategy.

- Seminars and workshops for mathematics teachers should be organized on regular basis with the intention of making them acquire skills and techniques required to effectively use blended strategy in the teaching and learning of mathematics.

- Curriculum planners and Policy makers should help to emphasis and encourage the use of blended strategy in the teaching and learning of mathematics at secondary schools.

- Information and Communication Technology (ICT) gadgets should be made available in school to enhance webbased learning.

\section{Suggestions for Further Studies}

This study investigated the effects of blended strategy on students' performance in Algebra. Based on the findings of this study, further studies in teaching and learning of mathematics are invited to replicate the model for other themes of mathematics.

\section{References}

i. Achor, E.E., Imoko, B.I. \&Uloko, E.S. (2009). Effect of ethnomatics teaching approach and interest on student's achievement in Locus.Benue J. Research in Science Education. 1(1) 81-91

ii. Aiken, R. L. (2000). Psychological testing and assessment. Boston, MA: Allyn and Bacon.

iii. Almasaeid, T. F (2014): The effect of using blended learning strategy on achievement and attitudes in teaching science among 9th grade students. European Scientific Journal. 10(31), 133 - 145

iv. Akinsola, M.K. \& Awofala, A.O.A. (2008).Effect of problem content and reasoning complexity on mathematics problem solving achievement and transit of secondary school students. European journal of scientific research. 20(3), $641-651$

v. Arigbabu, A.A.\& Mji,A. (2004). Is gender a factor on mathematics performance among Nigerian pre-service teachers? Sex Roles: A Journal of Research, 51(II), 749- 753

vi. Awodeyi, A.F, Akpan, E.T. \& Udo, I. J (2014): Enhancing teaching and learning of mathematics: adoption of blended learning pedagogy in University of Uyo. International Journal of Science and Research 3(11)

vii. Ayuba, I. \& Timayi, J. M. (2018). Impact of computer based-instruction on students' performance and retention in algebraic word problems, Kaduna state, Nigeria Abacus (Mathematics Education Series), 43(1), 7 - 13

viii. Bailey, J. and Martin ,N.(2013) Blended learning implementation guide, foundation for excellence education. Washington, D.C

ix. Brandy H. (2016). An Examination of Blended Learning and the Traditional Classroom Using Achievement Scores. Unpublished thesis submitted to educational technology department of Walden University. 
x. Cracraft L. (2015) Effect of Blending Learning on Student's Percent Increase in Assessment Scores. Unpublished research paper submitted to the Educational leadership faculty Northwest Missouri State University Missouri.

xi. Eisenhart, M., Borko, H., Underhill, R., Brown, C., Jones, D., \& Agard, P. (1993). Conceptual knowledge falls through the cracks: Complexities of learning to teach mathematics for understanding. Journal for Research in Mathematics Education, 24(1), 8-40. https://doi.org/10.2307/749384

xii. Fakhir, Z. (2015): The Impact of Blended Learning on the Achievement of the English Language Students and their Attitudes towards it. Unpublished thesis submitted to the department of English Language and Literature Faculty of Arts and Sciences Middle East University

xiii. Ginga, U.A, Muhammed, B, \& Usman N. (2019) Effect of reciprocal teaching strategy on students' performance in word problem leading to simultaneous equations for creativity in basic secondary and tertiary education in Yobe state. Abacus (Mathematics Education Series) 44(1). 250 - 259

xiv. Gynther, K. (2005). Blended Learning. Unge Paedagoger, Kobenhavn

xv. Heinze, A. and Procter, C. (2004): Reflections on the use blended learning. Education in a changing environment conference proceeding, University of Safford. 13 $3^{\text {th }}-14^{\text {th }} \quad$ September, 2004.

xvi. Hinampas, R.T, Murillo, C. R, Tan, D.A and Roxette U. Layosa, R. U (2018): Blended learning approach: effect on students' academic achievement and practical skills in science laboratories. International journal of scientific \& technology research, 7(11), $63-69$

xvii. Ilorah S. O, Adeniji J. K. and Odeyemi A. O (2018) Blended Learning Instructional Strategy for Enhancing Students' Academic Performance in Physics Practicals in Port Harcourt Metropolis International Journal of Innovative Social \& Science Education Research 6(2):114-125.

xviii. Joefel S. S. (2014): Factors affecting underachievement in mathematics, Global Summit on Education GSE 2014. 4-5 March 2014, Kuala Lumpur, mathematics improvement project in nation building. Journal of Mathematical Sciences Education. 1(1)1-19

xix. Kuo, Y., Belland, B. R., Schroder, K. E., \& Walker, A. E. (2014) K-12 teachers' perceptions of and their satisfaction with interaction type in blended learning environments Distance Education, 35(3), 360-381 doi:10.1080/01587919.2015.955265

$x x$. Lin Y, Tseng C and Chiang P (2017). The effect of blended learning in mathematics course. EURASIA Journal of Mathematics Science and Technology Education. 13(3):741-770

xxi. Mohamed, L., \& Waheed, H. (2011). Secondary students' attitude towards mathematics in a selected school of Maldives. International Journal of Humanities and Social Science, 1(15), 277-281.

xxii. NERDC (2007): Nigeria Education Research and Development Council. Mathematics curriculum for senior secondary school.

xxiii. NERDC (1985): Nigeria Education Research and Development Council. Mathematics curriculum for senior secondary school.

xxiv. Salameh, H. (2005). Blended Learning: The Natural Development of E Learning, E -Learning Forums, retrieved from :www.elearning.edu.sa/forum/attachment.php? attachmentid=635\&d=118206521

xxv. Usman, M.A and Musa D, C. (2019) Concept mapping instructional strategy and senior secondary students performance and interest in Algebra in Bauchi state. Abacus (Mathematics Education Series) 44(1). 236 - 242

xxvi. West African Examination Council (2015).Chief examiner's report.

xxvii. West African Examination Council (2016).Chief examiner's report.

xxviii. West African Examination Council (2017).Chief examiner's report.

xxix. Wilson, J.W. et al. (2013) 6 Models of Blended Learning, Retrieved June 28, 2015 from Dream box http://www.dreambox.com/blog/6- models-blended-learning\#sthash.6vnmJzCZ.dpuf

xxx. Yaghmour, K. S. (2016) Effectiveness of Blended Teaching Strategy on the Achievement of Third Grade Students in Mathematics. Journal of Education and Practice. 7(5), 65 - 73 